\title{
PENGARUH SOCIAL MEDIA MARKETING TERHADAP BRAND AWARENESS DAN PURCHASE INTENTION (Studi Kasus : SMK Kesehatan Sanjiwani Gianyar)
}

\author{
I Dewa Putu Gede Wiyata Putra ${ }^{1}$ \\ Made Dona Wahyu Aristana ${ }^{2}$
}

\author{
STMIK STIKOM Indonesia, Bali, Indonesia ${ }^{1,2}$ \\ Email: dewa.wiyata@stiki-indonesia.ac.id ${ }^{1}$ aryztana@stiki-indonesia.ac.id ${ }^{2}$
}

\begin{abstract}
This study examined influence of social media marketing on brand awareness and purchase intention. SMK Kesehatan Sanjiwani Gianyar conducts social media marketing through paid promotions on Instagram and Facebook to increase brand awareness and interest of junior high school students to attend SMK Kesehatan Sanjiwani Gianyar. Data of 2017-2019 shows a decrease in the number of students, even though paid promotions have been carried out through Facebook and Instagram. Method in this study was Structural Equation Modeling (SEM) with the PLS Sample in this research was 100 junior high school students in areas Gianyar, Denpasar, Bangli, Klungkung and Badung regencies. Results in this study shows that social media marketing doesn't have a significant effect on purchase intention. Social media marketing through paid promotions on Instagram and Facebook creates brand awareness. Increase purchase intention the school must convince the public that school has good quality by exploring the excellence and uniqueness of the school.
\end{abstract}

Keywords: Social Media Marketing; Brand Awareness; Purchase Intention

\begin{abstract}
ABSTRAK
Penelitian ini mengkaji pengaruh social media marketing terhadap brand awareness dan purchase intention. SMK Kesehatan Sanjiwani Gianyar melakukan social media marketing melalui promosi berbayar instagram dan facebook untuk meningkatkan brand awareness dan minat siswa SMP untuk bersekolah di SMK Kesehatan Sanjiwani Gianyar. Data tahun 2017 - 2019 menunjukkan adanya penurunan perolehan jumlah siswa walaupun sudah dilakukan promosi berbayar melalui facebook dan instagram. Objek penelitian ini adalah 100 siswa dan siswi SMP dengan range usia 13 - 16 tahun diwilayah sekitar SMK Kesehatan Sanjiwani Gianyar yaitu Kabupaten Gianyar, Denpasar, Bangli, Klungkung dan Badung. Metode yang digunakan dalam penelitian ini adalah Structural Equation Modeling (SEM) dengan pendekatan PLS. Hasil penelitian ini menyatakan bahwa social media marketing tidak berpengaruh secara signifikan terhadap purchase intention. Social media marketing melalui promosi berbayar di instagram dan facebook menciptakan brand awareness. Meningkatkan purchase intention pihak sekolah harus meyakinkan masyarakat bahwa sekolah ini bermutu dengan menggali keunggualan dan keunikan sekolah.
\end{abstract}

Kata kunci: Social Media Marketing; Brand Awareness; Purchase Intention 


\section{PENDAHULUAN}

Pengguna internet di Indonesia mengalami peningkatan setiap tahun. Survey APJII mencatat pengguna internet di Indonesia pada tahun 2018 sebanyak 171 juta penduduk dimana 150 juta (86\%) penduduk pengguna internet mengakses media social (Katadata, 2019). Media sosial yang paling banyak digunakan adalah facebook diikuti oleh instagram dan youtube. Pengguna sosial media menjadi perhatian bagi para pemilik bisnis atau perusahaan untuk memasarkan produknya melalui social media marketing.

Social media marketing adalah strategi pemasaran barang dan jasa dengan menggunakan media sosial untuk membangun hubungan, komunitas, transaksi dan bertukar informasi dengan konsumen dan calon konsumen (Aliami dkk., 2018; Godey et al., 2016; Zulfikar \& Mikhriani, 2017). Social media marketing dapat mempengaruhi minat, ketertarikan, keputusan konsumen, dalam memilih suatu produk barang atau jasa, konsumen memilih produk yang sudah dikenalnya atau tidak asing (Leviana, 2019). Social media marketing digunakan

oleh pemilik bisnis atau perusahan untuk memperkuat brand awareness dan meningkatkan purchase intention sebuah produk.

Brand awareness adalah kemampuan konsumen untuk mengenali atau mengingat suatu bagian produk yg disebut merek (Herman, 2014). Brand awareness yang kuat tercipta melalui social media marketing dalam bentuk interaksi antara brand dengan konsumen (Maulani \& Brillyanes, 2019; Semuel \& Setiawan, 2018). Purchase intention atau minat beli adalah keinginan untuk memiliki produk yang muncul dalam diri konsumen sebagai dampak dari 
pengamatan dan pembelajaran konsumen terhadap suatu (Durianto, 2004). Susanti et al., (2018) menyatakan purchase intention adalah keinginan konsumen untuk membeli suatu produk atau jasa diwaktu yang akan datang. Purchase intention yang tinggi tercipta dari keunggulan perusahan dalam mengelola social media marketing.

SMK Kesehatan Sanjiwani Gianyar sejak tahun 2017 sudah melakukan social media marketing untuk meningkatkan brand awareness dan purchase intention siswa SMP. Data tahun 2017 - 2019 pada Tabel 1 menunjukkan SMK Kesehatan Sanjiwani Gianyar penurunan perolehan jumlah siswa walaupun sudah melakukan social media marketing melalui promosi berbayar instagram dan facebook.

Tabel 1.

Jumlah Siswa SMK Sanjiwani

\begin{tabular}{ccc}
\hline No & Tahun Ajaran & Jumlah Siswa \\
\hline 1 & $2015 / 2016$ & 110 \\
\hline 2 & $2016 / 2017$ & 125 \\
\hline 3 & $2017 / 2018$ & 120 \\
\hline 4 & $2018 / 2019$ & 92 \\
\hline 5 & $2019 / 2020$ & 75
\end{tabular}

Sumber: Data internal SMK Sanjiwani,2019

Berdasarkan permasalahan tersebut dilakukan penelitian di SMK Kesehatan Sanjiwani Gianyar untuk melihat pengaruh social media marketing terhadap brand awareness dan purchase intention. Hasil penelitian ini diharapkan dapat membantu pihak sekolah dalam menentukan strategi untuk meningkatkan minat siswa SMP bersekolah di SMK Kesehatan Sanjiwani Gianyar. 
Kerangka konseptual dalam penelitian ini dapat dilihat pada Gambar 1. Social media marketing adalah variabel bebas, Brand Awareness dan Purchase Intention adalah variabel terikat.

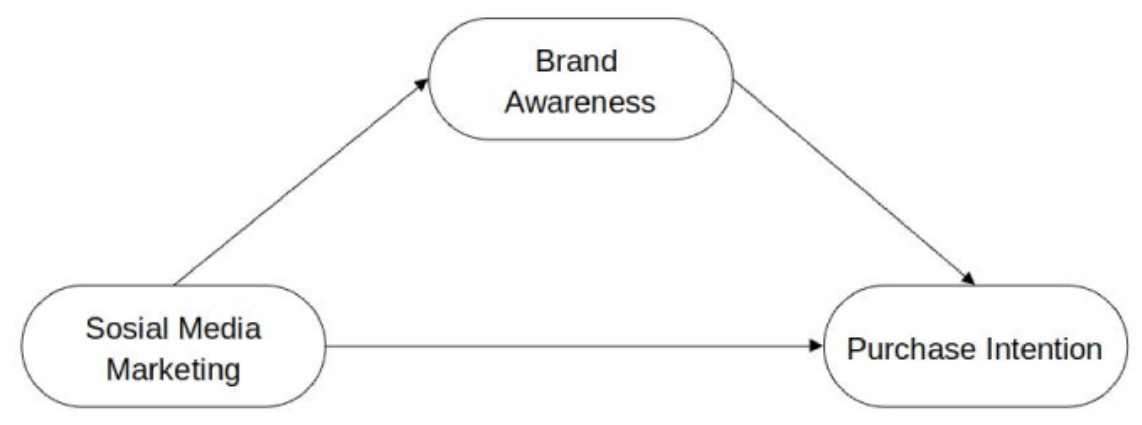

Gambar 1.

Hubungan antar variabel independen dan dependen

Hipotesis yang diajukan dalam penelitian ini:

H1 : Social media marketing berpengaruh signifikan terhadap Brand Awareness.

H2 : Social media marketing berpengaruh signifikan terhadap Purchase intention.

H3 : Brand awareness berpengaruh signifikan terhadap purchase intention.

H4 : Social media marketing berpengaruh signifikan terhadap purchase intention melalui brand awareness.

\section{METODE PENELITIAN}

Penelitian ini menggunakan analisis deskriptif yang menggambarkan objek penelitian melalui data sampel tanpa analisis dan kesimpulan (Sugiyono, 2013). Variabel digambarkan dengan menggunakan nilai rata-rata jawaban 
responden. Partial Least Square (PLS) sebagai teknik analisis data dengan Structural Equation Model (SEM) yang berbasis varians.

Pengumpulan data penelitian ini dilakukan melalui wawancara dan kuesioner pada bulan Agustus tahun 2020. Wawancara dilakukan kepada Guru dan Staft SMK Kesehatan Sanjiwani Gianyar. Kuesioner menggunakan jenis pertanyaan tertutup yang diberikan kepada 100 siswa dan siswi SMP dengan range usia 13 - 16 tahun diwilayah sekitar SMK Kesehatan Sanjiwani Gianyar yaitu Kabupaten Gianyar, Denpasar, Bangli, Klungkung dan Badung. Kuesioner bersumber dari penguraian variabel penelitian menjadi item pertanyaan untuk responden. Definisi operasional variabel bisa dilihat pada Tabel 2.

Tabel 2.

Definisi Operasional Variabel

\begin{tabular}{|c|c|c|c|}
\hline Variabel & Keterangan & Indikator & Sumber \\
\hline $\begin{array}{l}\text { Social } \\
\text { Media } \\
\text { Marketing } \\
\text { X1 }\end{array}$ & $\begin{array}{l}\text { Social media marketing adalah aktivitas } \\
\text { memasarkan produk atau jasa melalui } \\
\text { social media. }\end{array}$ & $\begin{array}{l}\text { Participation \& Engagement } \\
\text { Openess } \\
\text { Conversation } \\
\text { Community }\end{array}$ & $\begin{array}{c}\text { (Mayfield, } \\
\text { 2008) }\end{array}$ \\
\hline $\begin{array}{l}\text { Brand } \\
\text { Awareness } \\
\quad \text { y1 }\end{array}$ & $\begin{array}{l}\text { Brand awareness adalah kemampuan } \\
\text { calon pembeli atau konsumen untuk } \\
\text { mengenali maupun mengingat sebuah } \\
\text { merek dalam kondisi yang berbeda }\end{array}$ & $\begin{array}{l}\text { Konsumen paham seperti apa } \\
\text { merek itu. } \\
\text { Dapat mengenali merek diantara } \\
\text { merek pesaing. } \\
\text { Sadar akan keberadaan merek. } \\
\text { Konsumen membayangkan ciri } \\
\text { merek dengan cepat. }\end{array}$ & $\begin{array}{c}\text { (Keller, } \\
2006)\end{array}$ \\
\hline $\begin{array}{l}\text { Purchase } \\
\text { Intention } \\
\quad y 2\end{array}$ & $\begin{array}{l}\text { Purchase intention atau minat beli } \\
\text { konsumen adalah kemauan atau } \\
\text { keinginan konsumen dalam membeli } \\
\text { suatu produk mauapun jasa diwaktu } \\
\text { yang akan datang }\end{array}$ & $\begin{array}{l}\text { Perhatian (Attention) } \\
\text { Ketertarikan (Interest) } \\
\text { Keinginan (Desire) } \\
\text { Tindakan (Action) }\end{array}$ & $\begin{array}{l}\text { (Kotler \& } \\
\text { Keller, } \\
\text { 2009) }\end{array}$ \\
\hline
\end{tabular}

Sumber: Berbagai sumber,2020

\section{HASIL DAN PEMBAHASAN}

Uji Validitas diukur dari nilai AVE (Average Variance Extracted). Nilai

AVE > 0,5 artinya variabel mampu menggambarkan varian dari masing-masing 
indikatornya. Uji reliabitas diukur dari nilai composite reliability. Nilai Composite reliability $>0,7$ artinya semua item pertanyaan dalam penelitian ini adalah reliabel. Variabel dalam penelitian ini adalah valid dan reliabel. Hasil uji validitas dan reabilitas dapat dilihat pada Tabel 3.

Tabel 3.

Hasil uji Validitas dan Reabilitas.

\begin{tabular}{lccc}
\hline & $\begin{array}{c}\text { Cronbach's } \\
\text { Alpha }\end{array}$ & Composite Reliability & $\begin{array}{c}\text { Average Variance } \\
\text { Extracted (AVE) }\end{array}$ \\
\hline BA & 0,947 & 0,962 & 0,864 \\
\hline PI & 0,964 & 0,973 & 0,902 \\
\hline SMM & 0,963 & 0,973 & 0,901 \\
\hline
\end{tabular}

Sumber : data diolah, 2020

Nilai R-square menjelaskan pengaruh variabel eksogen (independen/bebas) dalam menerangkan variabel endogen (dependen/terikat). Nilai R Square dapat dilihat pada Tabel 4.

Tabel 4.

Hasil $R$ Square

\begin{tabular}{ccc}
\hline & R Square \\
\hline BA & 0,388 \\
PI & 0,934 \\
\hline
\end{tabular}

Sumber : data diolah, 2020

Pengujian goodness-fit model menggunakan nilai predictive-relevance $\left(\mathrm{Q}^{2}\right)$. Nilai predictive-relevance diperoleh dengan rumus:

$$
\begin{aligned}
\mathrm{Q}^{2} & =1-\left(1-\mathrm{R}^{2} 1\right)\left(1-\mathrm{R}^{2} 2\right) \\
& =1-\left(1-0,388^{2}\right)\left(1-0,934^{2}\right) \\
& =1-(0,849)(0,128) \\
& =1-0,108 \\
& =0,892 \text { atau } 89,2 \%
\end{aligned}
$$


Penelitian ini memiliki nilai yang relevan dimana 89,2\% variabel Purchase Intention dapat dijelaskan oleh variabel yang digunakan sedangkan 10,8\% dijelaskan oleh faktor lain.

Uji path analysis PLS dilakukan menggunakan SmartPLS. Hasil uji adalah sebagai berikut:

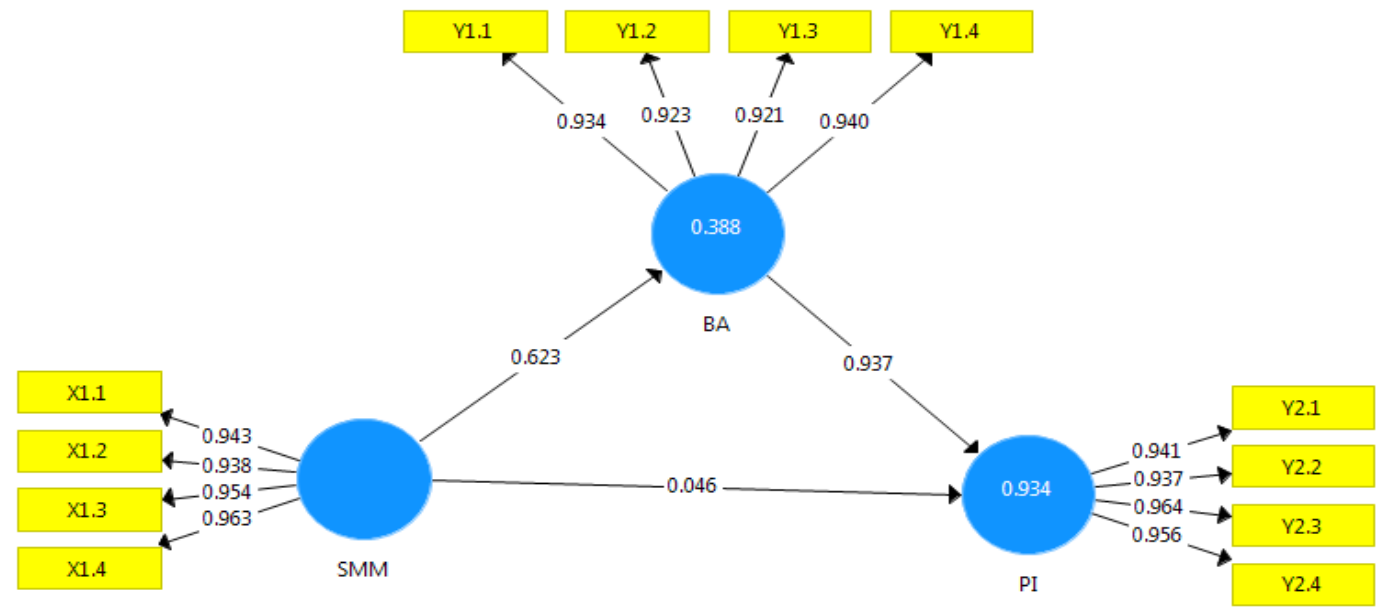

Gambar 2.

Hasil Analisis PLS

Penelitian ini memiliki hasil social media marketing (SMM) berpengaruh terhadap brand awareness (BA), dengan koefisien parameter 0,623 dan $T$ statistics 6,755 dengan $t$-Statistics $\pm 1,96$ dan signifikan pada $\alpha=0,05$ sehingga hal ini sesuai dengan penelitian yang dilakukan oleh Semuel \& Setiawan (2018) yang menyatakan sosial media marketing berpengaruh terhadap brand awareness.

Social Media Marketing (SMM) tidak berpengaruh terhadap Purchase Intention (PI), dengan koefisien parameter 0,046 dan T-statistics 1,548 dimana nilai $T$-statistics lebih kecil dari 1,9. Penelitian ini tidak sesuai dengan penelitian yang dilakukan Priatni, Hutriana, \& Hindarwati (2020) yang menyatakan social 
media merketing berpengaruh terhadap purchase intention. Penyebab ketidaksesuaian penelitian ini adalah SMK Kesehatan Sanjiwani Gianyar adalah lembaga pendidikan, untuk meningkatkan purchase intention tidak cukup dilakukan dengan social media marketing. Pengelola SMK Kesehatan Sanjiwani Gianyar harus meyakinkan masyarakat bahwa sekolah ini bermutu dengan menggali keunggualan dan keunikan sekolah.

Brand Awareness (BA) berpengaruh terhadap purchase intention (PI), dengan koefisien paramater 0,937 dan T-statistics sebesar 41,671 dengan $t$ Statistics $\pm 1,96$ dan signifikan pada $\alpha=0,05$ sehingga hal ini sesuai dengan penelitian yang dilakukan Dwiyanti dkk., (2018) yang menyatakan brand awareness berpengaruh terhadap purchase intention.

Social media marketing (SMM) berpengaruh terhadap purchase intention (PI) melalui brand awareness (BI), dengan koefisien parameter 0,583 dan $T$ statistics sebesar 7,127. Penelitian ini sesuai dengan penelitian yang dilakukan oleh Maulani \& Brillyanes (2019) yang menyatakan social media marketing berpengaruh terhadap purhcase intention melalui brand awareness.

Hasil pengujian hipotesis penelitian ini ditunjukkan pada Tabel 5.

Tabel 5.

Hasil Inner Weight

\begin{tabular}{lrrrl}
\hline & $\begin{array}{l}\text { Original } \\
\text { Sample (O) }\end{array}$ & $\begin{array}{l}\text { Standard } \\
\text { Deviation } \\
\text { (STDEV) }\end{array}$ & $\begin{array}{l}\text { T Statistics } \\
(\mid \mathbf{O} / \text { STDEV|) }\end{array}$ & Kesimpulan \\
\hline SMM -> BA & 0,623 & 0,092 & 6,755 & Diterima \\
\hline SMM -> PI & 0,046 & 0,030 & 1,548 & Ditolak \\
\hline BA -> PI & 0,937 & 0,022 & 41,671 & Diterima \\
\hline SMM->BA-> PI & 0,583 & 0,082 & 7,127 & Diterima \\
\hline Sumber $:$ data diolah, 2020 & & & &
\end{tabular}

Sumber : data diolah, 2020 


\section{SIMPULAN DAN SARAN}

Penelitian ini menunjukan social media marketing menciptakan brand awareness yang kuat terhadap SMK Kesehatan Sanjiwani Gianyar, brand awareness berpengaruh terhadap purchase intention dan social media marketing berpengaruh terhadap purchase intention melalui brand awareness. Penelitian ini menyatakan social media marketing tidak berpengaruh terhadap purchase intention. Pihak sekolah untuk meningkatkan purchase intention harus meyakinkan masyarakat bahwa sekolah ini bermutu dengan menggali keunggulan dan keunikan sekolah. Penelitian ini memiliki jumlah sampel yang terlalu sedikit sehingga diperlukan penelitian selanjutnya dengan jumlah sampel lebih besar agar bisa melihat pengaruh social media marketing terhadap purchase intention.

\section{REFERENSI}

Aliami, S., Hakimah, E. N., Ayu, D., \& Fauji, S. (2018). Dampak Pengembangan Pemasaran Digital Pada Startup' S ( Studi Kasus Pada Wirausaha Baru ). Jurnal Administrasi Bisnis, 3(1), 73-87.

Durianto, D. (2004). Strategi Menaklukan Pasar Melalui Riset Ekuitas dan Perilaku. Nasional.

Dwiyanti, E., Qomariah, N., \& Tyas, W. M. (2018). Pengaruh Persepsi Kualitas, Nama Merek Dan Brand Awareness Terhadap Keputusan Pembelian. Jurnal Sains Manajemen Dan Bisnis Indonesia, 8(2).

Godey, B., Manthiou, A., Pederzoli, D., Rokka, J., Aiello, G., Donvito, R., \& Singh, R. (2016). Social media marketing efforts of luxury brands: Influence on brand equity and consumer behavior. Journal of Business Research, 69(12), 5833-5841. https://doi.org/10.1016/j.jbusres.2016.04.181

Herman, J. (2014). The ultimate beginner's guide to instagram. Retrieved February, 5, 2018.

Katadata. (2019). Retrieved August 12, 2019, from 
https://databoks.katadata.co.id/datapublish/2019/02/08/berapa-penggunamedia-sosial-indonesia

Keller, K. L. (2006). Conceptualizing, Measuring, and Managing Customer-Based Brand Equity. Journal of Marketing, 57(1), 1. https://doi.org/10.2307/1252054

Kotler, P., \& Keller, K. L. (2009). Manajemen pemasaran Jilid 1. In Jakarta.

Leviana, T. (2019). Pengaruh Social Media Marketing Terhadap Willingness To Pay Premium Price Melalui Brand Equity Pada Konsumen Estee Lauder. Agora, 7(1).

Maulani, L. S., \& Brillyanes, S. (2019). Pengaruh Social Media Marketing Terhadap Brand Awareness Serta Dampaknya Pada Purchase Decision ( Survei Online pada Followers Aktif Instagram dan Facebook Vauza Tamma Hijab ). Jurnal Administrasi Bisnis, 72(2), 148-156.

Mayfield, A. (2008). What is social media? iCrossing eBook. In Researching Language and Social Media. https://doi.org/10.4324/9781315771786-2

Priatni, S. B., Hutriana, T., \& Hindarwati, E. N. (2020). Pengaruh Social Media Marketing terhadap Purchase Intention dengan Brand Awareness sebagai Variable Intervening pada Martha Tilaar Salon Day Spa. Jurnal Ekonomi, Manajemen Dan Perbankan (Journal of Economics, Management and Banking), 5(3), 145. https://doi.org/10.35384/jemp.v5i3.165

Semuel, H., \& Setiawan, K. Y. (2018). Promosi Melalui Sosial Media , Brand Awareness , Purchase. Manajemen Pemasaran, 12(1), 47-52. https://doi.org/10.9744/pemasaran.12.1.47

Sugiyono. (2013). Metode Penelitian Pendidikan Pendekatan Kuantitaif, Kualitatif, dan R\&D. Metode Penelitian Pendidikan Pendekatan Kuantitaif, Kualitatif, Dan R\&D, pp. 283-393. https://doi.org/10.1007/s13398-0140173-7.2

Susanti, I. D., Astuti, R. D., Sariasih, F. A., \& Putra, Jo. L. (2018). Jurnal Mitra Manajemen ( JMM Online ). Jurnal Mitra Manajemen, 2(4), 273-285. Retrieved from http://ejurnalmitramanajemen.com/index.php/jmm/article/view/125/69

Zulfikar, A. R., \& Mikhriani. (2017). Pengaruh Social Media Marketing Terhadap Brand Trust Pada Followers Instagram Dompet Dhuafa Cabang Yogyakarta. Al-Idarah, 13(3), 1576-1580. 